\title{
EL PROYECTO HSHOUMA, EL ARTE COMO MOTOR DE CAMBIO SOCIAL
}

\author{
Carmen GARRATÓN MATEU* \\ Universidad de Granada
}

BIBLID [1133-8571] 26 (2019) 09.1-24.

Resumen: El proyecto Hshouma, liderado por la activista feminista, Zainab Fasiki, propone recurrir al arte como herramienta para romper los tabúes existentes en la sociedad marroquí. Mediante una plataforma digital, novelas gráficas, cómics, ilustraciones y textos expresados en el dialecto marroquí -el darija-, en inglés o en francés, se abordan cuestiones ligadas al cuerpo, a la sexualidad, a la discriminación, a la violencia y a la libertad y se invita a cualquiera a participar para ser «parte del cambio». En sus ilustraciones la artista muestra el cuerpo femenino al desnudo como medio de hacer frente a los convencionalismos y reivindicar la libertad personal, pero también como forma de «desnudar a la sociedad» y visibilizar estas cuestiones.

Palabras clave: Tabúes de la sociedad marroquí, Educación sexual, Igualdad de géneros, Cómic marroquí, hshouma.

\begin{abstract}
Hshouma project, the art as a driving force in social transformation». Hshouma project, led by the feminist activist, Zainab Fasiki, uses art as a tool to break Moroccan society's taboos. Through a digital platform, graphic novels, comics, illustrations and texts in Moroccan Arabic -

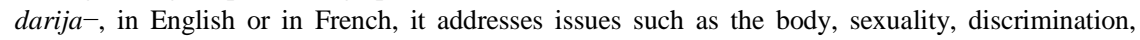
violence and freedom. The project also invites anyone to be part of the change. The artist shows the naked feminine body in her illustrations as a way to face social conventions and to claim personal freedom, but also as a way to undress society and to make these topics visible.

Key words: Moroccan Society's Taboos, Sex Education, Gender Equality, Moroccan comic, hshouma.
\end{abstract}

الملخص: 》 مشروع حشومة: الفن كمحرك للتغيير الاجتماعي". مشروع حشومة، بِقيادة الناشطة النسائية زينب فاسيكي

* $\quad$ Miembro del Grupo de Investigación Estudios Árabes Contemporáneos de la UGR. E-mail: carmen.garraton@uca.es. Código Orcid: 0000-0002-9095-8209. 


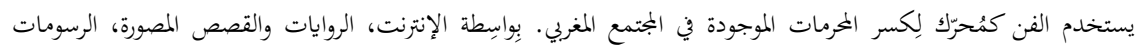

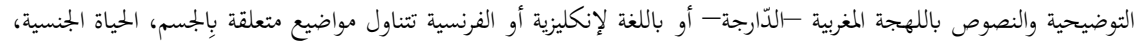

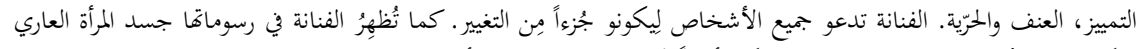

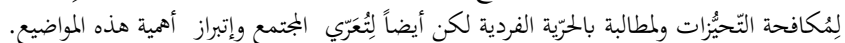

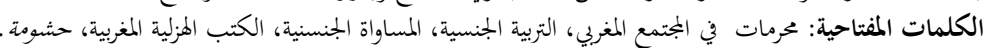

\section{Génesis del proyecto hshouma}

La palabra $h$ shouma ${ }^{(1)}$ significa «vergüenza» en el dialecto marroquí y es el término que se utiliza para hacer referencia a los tabúes existentes en la sociedad. Se trata de un sentimiento «mezcla de pudor, vergüenza, incomodidad, culpabilidad, prohibición, de no-decir» (Gassim 2015: 104). La hshouma dicta, controla y prohíbe. Con este nombre vio la luz el proyecto visual liderado por Zainab Fasiki (n. 1994, Fez), ingeniera mecánica industrial, activista feminista y dibujante autodidacta. Su propia experiencia, tras sufrir una depresión a los 19 años a causa de la discriminación existente en el ámbito de la mecánica, del acoso callejero cotidiano y del control familiar, la llevó a encontrar en el dibujo una vía de escape que le permitiera vivir como ella desease (Fasiki 2019). Tras instalarse en Casablanca en 2014, comenzó a trabar contactos con diferentes organizaciones para desarrollar su pasión artística. Ampliamente seguida en las redes sociales se dio a conocer al público en general por su participación, junto a otros artistas, como dibujante en la revista satírica Skefkef ${ }^{(2)}$.

En 2017 publicó su primera obra en solitario, un cómic de 70 páginas titulado Omor (Cosas) en el que, sus tres protagonistas, denuncian las trabas que experimentan las mujeres marroquíes en su vida cotidiana a causa de la desigualdad de géneros imperante en Marruecos ${ }^{(3)}$. En este cómic, la autora se inspira en su propia persona para dibujar sus personajes femeninos, al igual que hará en sus trabajos posteriores.

La agresión sexual sufrida en el verano de ese mismo año por una chica

(1) En árabe, حشومة

(2) En árabe, سكفنفم.

(3) Entrevista de TV5 Monde de 21/05/2017 <https://www.youtube.com/watch?v=kEnouSi81g> [16/10/2016]. 
discapacitada en un autobús de Casablanca $^{(4)}$ supuso el detonante para que Fasiki denunciara abiertamente la violencia y el acoso contra las mujeres ${ }^{(5)}$. Con ocasión de este suceso publicará una ilustración con el texto «los autobuses están hechos para transportar a la gente no para violar a las chicas ${ }^{(6)} \gg$. La imagen, que muestra a una mujer violentada y semidesnuda generará gran impacto en Marruecos y su autora se verá envuelta en una polémica en la que la semi desnudez del personaje dibujado generará más insultos y rechazo que el propio hecho denunciado.

Entre tanto prosigue sus colaboraciones en la revista Skefkef donde publicará en el n. 6 un cómic en darija protagonizado por una heroína femenina Super Khadija ${ }^{(7)}$. Así mismo, en mayo de 2018, publicó el cómic al-mufíd fí altarbiyya al-ğinsiyya ${ }^{(8)}$ (Lo esencial en la educación sexual), en el n. 9 de la citada revista, donde trata, también en darija, temas como la pubertad o las relaciones sexuales fuera de matrimonio, lo que le granjeó muchas críticas en su país acusándola de «perversión»(El Adnani 2018). Su objetivo era llegar al mayor número de jóvenes para responsabilizarlos y sensibilizarlos para que «combatan las ideas obscurantistas que consideran que todo lo que está relacionado con el sexo es una materia que molesta» (El Adnani 2018).

En otro ámbito, en octubre de 2018, Fasiki publicó el cómic Feyrouz Versus The World, esta vez en inglés. A lo largo de treinta y seis páginas relata la historia, con tintes autobiográficos, de una mujer joven, habitante de un país inventado de la región MENA (entre Irán y Marruecos) que sueña con recorrer el mundo. Esta obra afronta la problemática del peso que la sociedad conservadora ejerce sobre la mujer que desee materializar sus aspiraciones y salir de su entorno. Se alude también al conflicto generacional entre padres e hijos poniendo de relieve como las propias madres son, con frecuencia, las principales artífices de la preservación de la sociedad patriarcal tradicional, tema recurrente y presente en otros trabajos como Des mères contre les femmes, de

(4) Noticia difundida en diversos medios, <https://bit.ly/2MZMfRQ> [16/10/2019].

(5) Declaraciones de Z. Fasiki para Franceinfo [Brut 25/08/2017]:

<https://www.francetvinfo.fr/societe/droits-des-femmes/agression-au-maroc-on-est-toutesconcernees_2342095.html> [16/10/2019].

(6) Texto original: Buses are made to transport people not to rape girls, <https://www.wiriko.org/artes-visuales/zainab-fasiki/\#jp-carousel-25814> [16/10/2019].

(7) En árabe, سوبر خدية, aparecido en el n. 6 de Skefkef <https://bit.ly/2MUJRLX> [16/10/2019].

(8) Texto original: المفيد في التربية الجنسية 
Lacoste-Dujardin (1985), donde la etnóloga afirma que las madres son conscientes de que «no hacen sino perpetuar un rol tradicional reconocido a las mujeres consistente en mantener las políticas puestas en obra por los hombres» (Lacoste-Dujardin 1985: 53) lo que ocasiona que las hijas se encuentren «presas» de una situación cuya única solución es la obediencia pasiva a sus madres, que ejercen sobre ellas una «incontestable opresión» (ibid. 56). Feyrouz, la protagonista, sueña con la libertad en el seno de una familia conservadora y religiosa, a la que debe convencer de que viajar no implica abandonar su propia cultura, y se queja de que la educación tradicional no otorgue las mismas libertades a los hijos que a las hijas (Fasiki 2018b: 13-14). Esta cuestión fue objeto de una encuesta realizada entre jóvenes urbanos de Casablanca (Grousset 2002) que puso de manifiesto como las hijas solían entrar en conflicto con los padres principalmente por la asignación de las tareas domésticas y por las dificultades para realizar actividades relacionadas con el tiempo libre, mientras que los conflictos entre hijos y padres eran principalmente por motivos laborales o por los estudios, gozando de más libertad (Grousset 2002: 256). Las chicas permanecen más tiempo con la familia, ya sea viendo la televisión, leyendo o realizando tareas domésticas. La práctica del deporte suele beneficiar a los hombres puesto que más de un 50\% de las chicas no practican ninguna actividad física (Grousset 2002: 260).

La difusión de todos estos trabajos conducirá finalmente en la creación del proyecto Hshouma, con ocasión de la estancia artística llevada a cabo por Fasiki en Madrid (España) en $2018^{(9)}$. La idea original fue la creación de una plataforma digital educativa abierta a la participación de todo el mundo, así como la realización de exposiciones artísticas y la difusión de las obras a través de diversos soportes. En sus inicios, la página web del proyecto ${ }^{(10)}$ enumeraba y $^{-}$ describía una serie de materias consideradas tabúes en Marruecos, con un tono didáctico y reivindicativo. Los primeros frutos del proyecto fueron una serie de exposiciones y un primer trabajo impreso, un breve folleto de 12 páginas en blanco y negro, en formato cómic, titulado Hshouma (Fasiki 2018a) en el que su autora presenta y explica con ayuda de textos e ilustraciones los objetivos del

(9) Estancia llevada a cabo en Matadero, con la colaboración de los artistas del Queens Collective de Marrakech y la participación de la AECID, entre el 21/05/2018 y el 29/06/2018 <https://www.queenscollective.org/copy-of-matadero-queens> [16/10/2019].

(10) La web original ha sido sustituida por la versión <https://www.hshouma.com/> [16/10/2019]. 
proyecto, y enumera las cuestiones tabúes que previsiblemente serían desarrolladas en la web y un libro posterior. Este trabajo está redactado en inglés y va acompañado de cinco ilustraciones que incluyen pequeñas frases escritas en darija con grafía árabe. Todos los dibujos, excepto el último, que es un autorretrato de Fasiki, representan a mujeres completamente desnudas, y en ocasiones sin depilar, exhibiéndose sin complejos, y todas tienen la particularidad de mostrar los ojos en blanco, sin pupilas para evidenciar que, en palabras de la artista «las mujeres son como estatuas que no se pueden mover y siempre están controladas por la sociedad y los medios» (Ávalos 2018). En una primera ilustración aparece la frase «el control de la libertad de la persona es perjudicial para la salud ${ }^{(11)} \gg$ (Fasiki, 2018a: 4). La segunda ilustración corresponde a una mujer con cabeza de cordero, crotal incluido, ofreciendo un tayín en el que aparece el mismo número del crotal, acompañada de la frase «guía mi alma hacia $\mathrm{ti}^{(12)}$ » (ibid. 6), en alusión metafórica al tradicional sacrificio del cordero. El siguiente dibujo corresponde a otra mujer sentada sobre una alfombra tocando un instrumento con la frase «la música cura todas las enfermedades ${ }^{(13)} \gg$ (ibid. 8), posiblemente en respuesta a las tendencias fundamentalistas que consideran pecado la música (Topper 2019). En la cuarta ilustración aparece una joven mujer bereber con un tatuaje tradicional en la frente, sin depilar, acompañada de la frase «esta belleza solo está presente en el hammām ${ }^{(14)} \gg$ (Fasiki 2018a: 10), único lugar donde las mujeres marroquíes pueden exponer sus cuerpos en público. La obra concluye con el autorretrato de la autora acompañado de la frase, en inglés ${ }^{(15)}$, «yo no estoy rompiendo las leyes, yo sólo estoy rompiendo los tabúes» (Fasiki 2018a: 12).

Tanto en las ilustraciones de este trabajo impreso como los dibujos presentados en diversas exposiciones los mensajes escritos son cortos pero unidos a la fuerza de las imágenes producen un potente impacto visual, formato bastante efectivo en un país en el que la práctica de la lectura no está muy extendida (UNDP 2016: 27) ${ }^{(16)}$. La propia autora protagoniza al desnudo muchas

(11) Texto original: السيطرة على حريّه الناس ضارّة بالصحمّة

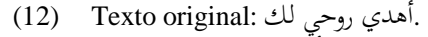

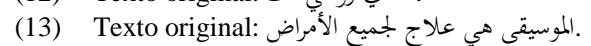

(14) Texto original: هذا الجمال موجود فقط في الحمّام الحمّام.

(15) Texto original: I am not breaking the laws, I am just breaking the taboos.

(16) Según este informe de Naciones Unidas, los marroquíes dedican de media 57 horas al año a la lectura. 
de sus ilustraciones como en la que aparece rodeada por una serpiente símbolo del pecado junto a la expresión en darija «métete en tus asuntos ${ }^{(17)}$ » y el texto en inglés «soy libre», mostrándonos su personal visión del feminismo y del arte.

El recurso al cómic o a la novela gráfica ${ }^{(18)}$ para poner de manifiesto los tabúes ligados a la sexualidad y a la falta de libertad en el contexto de los países musulmanes no es ninguna novedad. En 2016 Jane Deuxard y el ilustrador Zac Deloupy publicaron Love story à l'iranienne. Se trataba de un reportaje periodístico en forma de cómic en el que se recogen las inquietudes de los jóvenes iraníes y sus dificultades para poder llevar una vida sexual normalizada y libre en un país que castiga severamente cualquier relación fuera del matrimonio. Esta obra resultó ganadora en 2017 de la $23^{a}$ edición del Premio Franceinfo de cómic de actualidad y reportaje ${ }^{(19)}$. Otro caso más reciente es el de la novelista franco-marroquí Leila Slimani y la ilustradora Laetitia Coryn que, en 2017, publicaron Paroles d'honneur. Esta obra, constituye un reportaje en el que las mujeres toman la palabra para denunciar la hipocresía existente en Marruecos en torno a la sexualidad, un país donde las mujeres solo tienen la opción de permanecer vírgenes o contraer matrimonio, condenando el deseo y la libertad de amar. En esta obra las mujeres se debaten entre la idea de liberarse de la opresión y el peso de la tradición y la religión. Se incluye también la transcripción de entrevistas y testimonios de personas reconocidas en distintos ámbitos, ya sea médico, político, teológico, periodístico, etc., que tras ser presentadas mediante cortas biografías contribuyen a documentar con más exactitud la situación reflejada. Al igual que sucede con la obra de Fasiki, Slimani también aparece reflejada en las páginas de su libro para presentar y explicar cómo llevó a cabo su trabajo y cuál fue su fuente de inspiración.

Sin embargo, en el caso de Fasiki, el cómic impreso es solo una parte de su proyecto ya que las redes sociales han jugado un papel preponderante en la difusión y materialización del mismo. Internet se ha convertido en un aliado

(17) Textos originales: Dkhol so9 rassek, I am free <https://bit.ly/2MZnrJm> [16/10/2019].

(18) La línea que separa al comic de la novela gráfica no está claramente definida. Si bien existen distinciones los defensores del comic consideran que este género tiene la suficiente entidad para abarcar cualquier temática por lo que no necesita asociarse a otras modalidades creativas como la novela gráfica <https://blogs.ua.es/bibliotecauniversitaria/2015/06/02/el-comic-y-lanovela-grafica/> [16/10/2019].

(19) <https://www.livreshebdo.fr/article/love-story-liranienne-remporte-le-prix-franceinfo-de-labd-dactualite-2017> [26/10/2019]. 
esencial y muy poderoso para dar visibilidad a las reivindicaciones. Este tipo de herramientas comunicativas digitales permite denunciar las desigualdades de género y las violencias y contribuye a su erradicación. En el caso de las mujeres el espacio digital les permite revertir su «posición de víctimas a indignadas proactivas» que por este medio consiguen convertirse en «sujetos de enunciación de los discursos presentes en la sociedad global actual» (Zurbano et alii, 2016: 142). Así mismo, el desarrollo de portales educativos en internet resulta muy útil para los jóvenes que pueden por esta vía escapar de la censura familiar e institucional y constituye un medio de movilizar y sensibilizar a este sector de la población (Velasco de Castro 2019: 48).

El último fruto del proyecto ha sido el cómic publicado por Fasiki en 2019 bajo el título Hshouma. Corps et sexualité au Maroc, al que se dedica de manera casi exclusiva la página web del proyecto. No obstante, la citada web mantiene operativa la sección de contacto a la que cualquier persona puede escribir enviando ideas o sugerencias. Así mismo el proyecto sigue presente en Facebook con el mismo nombre ${ }^{(20)}$ cumpliendo la finalidad de plataforma de difusión de la obra de la artista y de sus puntos de vista sobre las cuestiones más controvertidas en la sociedad marroquí, de las que pasamos a ocuparnos a continuación.

\section{El tabú en la cultura marroquí}

Un tabú es algo prohibido o de lo que no se puede hablar con los demás y puede afectar a cualquier ámbito, sobre el que se impone el silencio. Para entender el tabú hay que contraponer la idea de «justicia o equidad» a lo que a menudo se considera una emoción o sentimiento de vergüenza (hshouma) y a la forma de esconder, exhibir o ajustar a las demandas de la situación cada caso, así como a la forma de relacionarse con los demás (Ossman 2002: 77). Para la mentalidad tradicional la «mujer ideal» es aquella que es 'ā $q l^{(21)}$ (razonable), es decir, la que se comporta bien, actúa con propiedad en la vida social, y está en sintonía con su posición. Por ello, la hshouma comprendería dos aspectos: la vergüenza y la culpa, por no «adaptarse» a la norma social. «Una palabra no puede ser dicha», sentencia, controla y prohíbe la hshouma, afectando a ricos y pobres, hombres y mujeres y muy especialmente a la mujer joven. La vergüenza

(20) <https://www.facebook.com/hshouma/> [16/10/2019].

(21) Del árabe: عاقلة. 
por lo tanto no solo es cuestión de ser visto sino de «ser visto por un observador con una cierta visión». Es un código al que nos ajustamos y que regula toda nuestra existencia. Es algo que asusta porque el descrédito no solo recae sobre los hombros del «culpable» sino sobre todos los que le rodean (Ossman 2002: 78). La vergüenza de uno además no es la vergüenza de otro, la del joven no es la misma que la del adulto, la de la mujer no es la misma que la del hombre, la de la ciudad no es la misma que en el campo.

En la sociedad marroquí existen aún muchos temas de los que no se puede hablar ni siquiera el ámbito de la familia o de los centros educativos. En el ámbito público, tradicionalmente se han considerado temas tabúes la monarquía -la salud del rey o su situación matrimonial-, las críticas al islam o la cuestión del Sáhara Occidental. Pero, en el presente trabajo, vamos a centrarnos en otra serie de tabúes ligados principalmente al cuerpo, a la sexualidad y a la libertad personal. La falta de comunicación que provoca «tabuizar» estos temas genera problemas de diversa índole social y fomenta la transmisión de informaciones erróneas sobre asuntos serios que necesitarían de programas educacionales profesionales. Este hecho, afecta especialmente a los jóvenes y adolescentes (10-19 años) en un país donde representan casi a un cuarto de la población (Grousset 2002: 253). La mayor parte de estos jóvenes recibe la información de la escuela o de la televisión, pero al tener dicha información una dimensión colectiva no permite el diálogo ni recibir unas nociones personalizadas y adaptadas a las necesidades de cada uno (Grousset 2002: 260).

Estos problemas se ven agravados en aquellos casos en los que el tabú va más allá de su consideración moral o religiosa y entra en el ámbito de lo penal, confundiéndose con el delito y poniendo en entredicho las libertades individuales. El ejemplo más evidente es la prohibición de toda relación sexual fuera del matrimonio ya que el artículo 490 del Código Penal marroquí(22) estipula que serán castigadas con la pena de prisión de un mes a un año, «todas las personas de distinto sexo que, no estando unidas por vínculos de matrimonio, mantengan entre ellas relaciones sexuales». Esta prohibición afecta especialmente a las mujeres ya que la pérdida de la virginidad puede acarrear serios problemas sociales, y mucho peor aún en el caso de llegar a producirse un

(22) Code Pénal Marocain, versión del 5 de julio de 2018: <http://adala.justice.gov.ma/production/legislation/fr/Nouveautes/code\%20penal.pdf> [16/10/2019]. 
embarazo. En Marruecos las madres solteras están fuertemente estigmatizadas. Son rechazadas por la comunidad y sus hijos son discriminados por las leyes de familia en vigor, a pesar de que en muchas ocasiones los embarazos son el fruto de violaciones y abusos sexuales en el seno de sus propias familias. Sin embargo, constituyen una realidad social que no se puede negar y por ello existen numerosas ONGs en Marruecos que ya trabajan en la reinserción de estas madres aunque, en muchos casos, cuando se trata de chicas jóvenes, las nociones sobre educación sexual que reciben para evitar su «recaída»las «infantilizan, como si se ocultara el hecho de que han tenido / tendrán relaciones sexuales, creando nuevos códigos de pudor que vienen a reforzar al del pudor ordinario» (Capelli 2017). En un país en el que existe poca sensibilización sobre la cuestión de los anticonceptivos, las madres solteras se ven abocadas en ocasiones a abortar clandestinamente o a abandonar a sus bebés por temor a sufrir el rechazo de la sociedad (Fasiki 2019: 71-72). Algunos casos muy mediáticos ${ }^{(23)}$ logran escapar del rigor de las normas, pero lo habitual es que el aborto sea penado o que, en el caso de no interrumpir el embarazo, la mujer tenga que sufrir las consecuencias ante la sociedad que criminaliza el sexo fuera del matrimonio. Por su parte, el aborto está regulado en los artículos 449 a 458 del Código Penal que no solo castigan a la mujer que aborte, sino a todas aquellas personas que hayan contribuido a realizar o facilitar el aborto por cualquier medio. El único supuesto en el que se admite el aborto es el riesgo para la salud de la madre, reconocido por el artículo 453 del Código Penal, que, no obstante, requiere la autorización del marido salvo en caso de riesgo inminente para la vida de la mujer. Pero incluso, en este último supuesto la negativa del cónyuge puede suponer una pérdida de tiempo vital para la madre ya que el facultativo autorizado a realizar el aborto no podrá actuar hasta que no cuente con la autorización del médico jefe de la prefectura o de la provincia. Ante la demanda de ciertos sectores de la sociedad, en 2015 el rey Mohamed VI anunció la ampliación del derecho de aborto en tres supuestos -violación, incesto y malformaciones incurables del feto ${ }^{(24)}-$ sin embargo, el proyecto de ley

(23) Es el caso de la periodista Hajar Raissouni, condenada a prisión e indultada posteriormente en 2019 por los delitos da aborto y por haber mantenido relaciones sexuales extramatrimoniales <https://www.amnesty.org/es/latest/news/2019/10/morocco-release-of-journalist-jailed-afterbeing-accused-of-having-an-abortion/> [25/10/2019].

(24) <https://telquel.ma/2015/05/16/mohammed-vi-legalise-lavortement-au-maroc-nouveaux- 
que debía dar luz verde a esta iniciativa no ha sido aún adoptado por el Parlamento donde la presencia de los miembros de partidos islamistas constituye un obstáculo(25).

La homosexualidad también se considera un tabú y un delito en Marruecos. El artículo 489 del Código Penal castiga con penas de prisión de 6 meses a tres años y multa «al que cometa un acto impúdico o contra natura con un individuo de su sexo». Asimismo, el adulterio, que es una cuestión que incumbe a la pareja, también constituye un delito penado por el artículo 491 del Código penal, aunque la imputación solo procede a instancias del cónyuge «ofendido».

El denominador común de estos delitos es que afectan a la libertad individual al confundir categorías como pecado y delito. Esta situación procede del carácter público que tiene la religión, al considerarse el islam la religión del Estado $^{(26)}$. De este modo, las normas reflejan la moral y los valores islámicos y por ello se criminalizan conductas que en otros ámbitos desligados de la religión no serían consideradas delitos.

La cuestión que subyace es la falta de definición y de protección de las libertades individuales, especialmente en los países musulmanes, donde la comunidad o la familia se atribuyen la competencia de ejercer el control de la sociedad. Por ello, cualquier actitud o conducta que se «desvíe» de la norma social trazada por la moral islámica tradicional es rechazada y, como acabamos de mencionar, en ocasiones sancionada por la ley. Sectores reformistas como el Collectif Démocratie et Libertés ${ }^{(27)}$ vienen denunciando que, a pesar de que el texto constitucional de 2011, preveía avances en materia de libertades individuales, estos no se han materializado debido a la falta de valor por parte de los políticos (Bozonnet 2018).

Esta problemática afecta a todos los sectores de la población, pero en el

cas_1447111> [16/10/2019].

(25) <https://bit.ly/32ZAQa1> [16/10/2019].

(26) Artículo 3 de la Constitución marroquí

<https://www.amb-maroc.fr/_docs/_Nouvelle_Constitution_\%20Maroc_2011.pdf> [16/10/2019].

(27) Este colectivo tenía previsto organizar en 2018 un coloquio internacional sobre libertades individuales en Casablanca donde se iban a debatir temas sensibles como la homosexualidad, las relaciones sexuales fuera del matrimonio, las madres solteras, la igualdad hereditaria, etc. pero finalmente fue prohibido por las autoridades (Bozonnet 2018). 
caso de las mujeres se ve agravada hasta el punto de que la sociedad se atribuye el papel de controlar incluso su vestimenta, de ahí las polémicas frecuentes en torno a cuestiones como el uso del velo. Así mismo, las mujeres se encuentran con más obstáculos a la hora de desarrollar sus carreras profesionales, ya que hechos tan habituales como vivir sola o viajar sola, resultan problemáticos a día de hoy ante algunos sectores de la sociedad marroquí más conservadores. En estos ámbitos, las mujeres que se atreven a desafiar las normas sociales son a menudo blanco de insultos, acoso, abusos o violencia que en ocasiones cuentan con la connivencia de la sociedad, que tiene tendencia en estos casos a culpar a la víctima.

Según la Organización Mundial de la Salud, la violencia que sufren las mujeres está considerada la primera causa de muerte entre los 15 y los 44 años «por encima de guerras, accidentes de tráfico o cáncer». Las agresiones, y principalmente el acoso sexual callejero, se llevan a cabo a la vista de todos, como forma de someter a la mujer y de hacer patente a quién corresponde el uso de la fuerza (Zurbano Berenguer et alii, 2016: 140). En Marruecos sigue considerándose un tema sensible rodeado de silencio y miedo hasta el punto de que el propio término «acoso sexual» es poco utilizado por las mujeres que prefieren referirse al mismo como «un problema» (Zurbano Berenguer et alii, 2016: 151).

La web originaria del proyecto Hshouma hacía referencia a esta lacra que muchas mujeres sufren cotidianamente, por ello, con el respaldo del espacio colaborativo JawJab de Casablanca, y del colectivo Women Power ${ }^{(28)}$ creado por Fasiki en enero de 2018 para impulsar las carreras de las jóvenes mujeres artistas marroquíes, se publicó la obra Drawing a guide to stop street harassment, en la que colaboraron más de veinte mujeres con el objetivo de dar consejos para prevenir el acoso sexual o $t_{7 \text { arech }^{(29)}}$ en las calles de Marruecos,. Este trabajo, que alterna textos con ilustraciones, pretende ser una guía práctica para las mujeres y, entre otras cosas, se facilitan los datos de la aplicación Manchoufouch $^{(30)}$ para animar a las mujeres a denunciar, habilitando una serie

(28) <http://filmand.es/zainab-fasiki-arte-activismo-y-feminismo-contra-los-tabues/> [16/10/2019].

(29) En grafía árabe, تحرّش.

(30) La aplicación cuenta con el apoyo de la plataforma <https://manchoufouch.ma/> [16/10/2019]. 
de herramientas como la localización GPS de la agresión, así como un servicio técnico de asistencia a la víctima. El texto informa de las sanciones previstas en la Ley $\mathrm{n}^{\mathrm{o}} 103-13^{(31)}$ de 2018 para los casos de acoso callejero que llegan a alcanzar los seis meses de prisión, agravándose en caso de reincidencia. Además, dicha ley amplía el concepto de acoso a cualquier expresión, acto sexual, gesto, mensaje escrito, grabación o imagen (art. 503-1-1).

El problema del acoso ya había sido denunciado en otros trabajos artísticos, como el llevado a cabo por otra activista marroquí, Ahlem B. que también utiliza las redes sociales para exponer sus ilustraciones y sus historias. $\mathrm{Su}$ proyecto Harcèlement de rue: Et toi tu entends quoi, consistió en recoger entre 2011 y 2014 todas las expresiones que los acosadores proferían a las mujeres en la calle. Fruto de ello, resultaron una serie de cuarenta y siete ilustraciones con el texto de cada expresión recogida escrito en árabe marroquí (Zurbano Berenguer 2016: 153). Al igual que en el caso de Fasiki, el uso del darija contribuyó a que el mensaje llegara a más gente y el recurso al internet y a las redes sociales resultó ser más eficaz que las campañas promovidas en los medios tradicionales por facilitar el intercambio de ideas y por gozar de un carácter más reivindicativo.

La web del proyecto Hshouma además hacía hincapié en que la violencia no solo afecta a las mujeres, ya que hay muchos tipos de violencia de los que no se habla porque también son considerados tabúes, citando entre algunos supuestos los siguientes: violación, prostitución forzada, pedofilia, matrimonio infantil, violación marital, abuso infantil, crímenes de honor, violencia doméstica, mutilación genital masculina y femenina, transfobias, homofobias, etc. En la mayoría de estos casos se trata de una violencia basada en cuestiones de género, ya que la igualdad es otra de las asignaturas pendientes en Marruecos como pone de manifiesto que la discriminación siga estando amparadas por leyes como el Código de la Familia( ${ }^{(32)}$ o Moudawana, en el que numerosos artículos otorgan un trato desigual a las mujeres, especialmente en el ámbito familiar y hereditario, priorizando al hombre (Garratón Mateu 2017: 52-54), por

(31) Dahir $\mathrm{n}^{\mathrm{o}}$ 1-18-19 du 5 joumada II 1439 (22 février 2018) portant promulgation de la loi $\mathrm{n}^{\circ}$ 103-13 relative à la lutte contre les violences faites aux femmes.

(32) Code de la Famille Marocain, versión de 2016

<http://adala.justice.gov.ma/production/legislation/fr/Nouveautes/Code\%20de\%20la\%20Fam ille.pdf $>[16 / 10 / 2019]$. 
ello Hshouma pretende ser también un alegato en favor de la igualdad de géneros porque aunque la Constitución marroquí(33) reconoce la igualdad en derechos y libertades de hombres y mujeres, ésta no será efectiva hasta que ambos no gocen de las mismas oportunidades en todos los sectores, lo que actualmente no sucede en Marruecos donde la brecha de género es patente en distintos ámbitos ${ }^{(34)}$. El sistema patriarcal, muy arraigado, fomenta que los hombres sigan desempeñando los roles predominantes en el liderazgo político, la autoridad moral, los privilegios sociales y el control de la propiedad. Algunos trabajos sugieren que uno de los motivos por el que el machismo está tan implantado en Marruecos podría deberse además a la escasa participación de las mujeres en el «inacabado proceso de transición política hacia la democracia» (Velasco de Castro 2019: 40), afirmación que se ve avalada por hechos como la composición del nuevo gobierno marroquí, presentado el 9 de octubre de 2019, que solo cuenta con cuatro ministras de un total de 23 ministros ${ }^{(35)}$.

Muchas de estas cuestiones han sido desarrolladas por el proyecto Hshouma y tras un primer año de intenso trabajo se han plasmado en el cómic Hshouma. Corps et sexualité au Maroc del que vamos a ocuparnos en el próximo apartado.

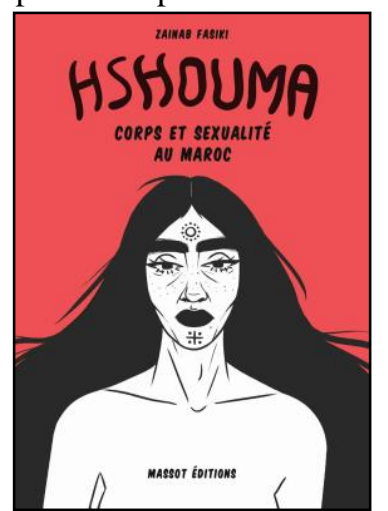

2. Temáticas planteadas en Hshouma. corps et sexualité au maroc y su reflejo en la sociedad

El primer aspecto que llama la atención de este trabajo es su formato. Al igual que en otros trabajos de Fasiki, las ilustraciones, principalmente en blanco y negro, con el color rojo de fondo, ocupan un lugar predominante, aunque en esta ocasión los textos, generalmente en francés, salvo alguna palabra o expresión en árabe, son más extensos. Como portada del libro se ha escogido el dibujo de una mujer bereber con el torso desnudo, los cabellos al aire y el

(33) Artículo 19 de la Constitución de 2011.

(34) Según el Global Gender Gap Report 2018, del Foro Económico Mundial, Marruecos estaría en el puesto 137 de 149 países analizados, es decir, lejos de alcanzar la paridad <http://reports.weforum.org/global-gender-gap-report-2018/data-explorer/\#economy=MAR> [16/10/2019].

(35) Fuentes oficial <http://www.maroc.ma/fr/content/la-liste-du-gouvernement> [16/10/2019]. 
rostro tatuado. Hay quien sugiere que los tatuajes bereberes reflejados en muchas de las ilustraciones de Fasiki supondrían una toma de posición frente al fundamentalismo importado de Arabia Saudí que considera pecado el hábito milenario de las mujeres bereberes de tatuarse el rostro (Topper 2019). Sin embargo, aunque hay una sucinta referencia al integrismo, se trata de una alusión expresa al origen bereber del norte de África y a la supuesta posición respetable de que gozaban las mujeres antes de la llegada de los árabes en el siglo VII, que supondrá el inicio de la dominación masculina al transformar a la sociedad norteafricana (Fasiki 2019: 3-4).

El objetivo de esta obra es hacer reflexionar al pueblo marroquí para conseguir una sociedad mejor eliminando los prejuicios (Fasiki 2019: 8).

En cuanto a los contenidos, el libro se divide en dos únicos capítulos: el primero, sobre el cuerpo y el segundo, sobre la sexualidad, temas que vamos a relacionar a continuación con la realidad actual marroquí.

\subsection{El cuerpo}

En este capítulo y a lo largo de cuatro apartados, se habla de la libertad y de la necesidad de cambiar la visión del cuerpo, ligado únicamente a la sexualidad. Se reivindica abiertamente acabar con la censura y tolerar el desnudo en el arte (Fasiki 2019: 11). Fasiki «dibuja su cuerpo desnudo porque es su herramienta de resistencia contra el machismo ambiente y contra todos aquellos que la quieren controlar ${ }^{(36)} \gg$.

Esta representación del cuerpo y su interpretación plantean un amplio terreno para la reflexión. El cuerpo desnudo se ha utilizado con diversos fines: provocar, publicitar, castigar, humillar, protestar o reivindicar, y es un recurso frecuente entre artistas de diversos ámbitos que se sirven de las nuevas tecnologías para dar visibilidad a sus obras y a los mensajes que intentan transmitir. Este es el caso de la artista canadiense de performance Dayna $\operatorname{McLeod}^{(37)}$, quien se sirve del humor para hacer reflexionar al público acerca de la manera en que los condicionamientos sociales y materiales inciden en el cuerpo, abordando temas tabúes como la menopausia, el útero o la condición sexual.

(36) Texto publicado el 21 de enero de 2019 en <http://www.wanacorp.fr/zainab-fasiki-artivistemarocaine/> [26/10/2019].

(37) <https://daynarama.com/> [26/10/2019]. 
Pero, aparte de esta utilización del cuerpo en el ámbito artístico, también encontramos casos en los que una determinada representación del mismo sirve para dejar constancia de la represión que sufre la mujer en algunas sociedades. Esta idea la encontramos en la utilización de imágenes o siluetas de mujeres sin rostro, cubiertas por el velo, en varias listas electorales para las legislativas del 4 de mayo de 2017 en Argelia «de acuerdo con las tradiciones ${ }^{(38)}$ ». Con esta estrategia se trataba de cumplir con las cuotas legales de candidatas, sin importar lo que estas «mujeres sin rostro» pudieran aportar a la política argelina. En el extremo opuesto, encontramos el recurso al cuerpo desnudo como forma de protesta. El cuerpo siempre ha sido utilizado por las feministas, tanto para señalar sus represiones en el patriarcado como para apuntar su poder transgresor (Reverter Bañon 2016: 172). Una de las manifestaciones más mediáticas es la de las activistas de FEMEN. Este grupo considera que su misión es protestar y que su arma son sus pechos desnudos, como forma de rebelión contra un patriarcado que reprime la sexualidad femenina (Reverter Bañon 2016: 173-174). Aunque se les critica que utilicen el cuerpo femenino, como ha venido haciendo la publicidad, ellas consideran que es un símbolo de empoderamiento ya que sus cuerpos en muchas ocasiones no cumplen con los cánones de belleza al uso, pero los muestran porque quieren atraer la atención hacia ellos y «obligar» a leer los mensajes que portan. En definitiva, lo esencial es que sea la propia mujer la que tenga la libertad, tal y como reivindica Fasiki, de decidir qué hacer con su propio cuerpo.

En otro orden de cosas, este capítulo pretende ser, además, una fuente de información básica con respecto a algunas cuestiones ligadas con la educación sexual como son: las transformaciones del cuerpo, los genitales, la menstruación, la fecundación, el desarrollo del feto, la identidad de género o la pubertad. La identidad de género y la diversidad sexo-genérica constituyen otro gran tabú al que se dedican varias páginas en las que se denuncian las amenazas y los insultos sufridos en Marruecos por las personas que no se identifican con el género socialmente asignado (Fasiki 2019: 24). Estos colectivos reivindican gozar de los mismos derechos que las personas heterosexuales, siendo ya numerosos países los que reconocen el matrimonio homosexual y los que

(38) <https://www.huffpostmaghreb.com/entry/en-algerie-des-candidates-aux-elections-sansvisages_mg_16288230> [26/10/2019]. 
permiten la adopción por parejas homosexuales, entre ellos España ${ }^{(39)}$. Sin embargo, en países como Marruecos, la homosexualidad se ha vivido en secreto, aunque, a partir de las primaveras árabes de 2011, han ido surgiendo movimientos en defensa de estos colectivos en Túnez, en Marruecos y en otros países de la región MENA que poco a poco se van agrupando para constituir una comunidad que pueda hacer oír sus reivindicaciones y sensibilizar a la población en los medios y en las redes sociales, como develó uno de los últimos informes de Human Rights Watch que recoge el testimonio de treinta y cuatro activistas LGBT de esta zona (HRW 2018). A su vez, en Marruecos, la Asociación Akaliyat ${ }^{(40)}$, es una de las organizaciones más activas que lucha abiertamente contra la criminalización y la discriminación trabajando en la defensa de los derechos de este colectivo.

La liberad corporal cierra este capítulo de la obra. Se trata de una reivindicación que afecta de manera muy especial a las mujeres por ser ellas las que están continuamente sujetas a las miradas y juicios de los demás. Las dificultades para salir libremente exponen continuamente a las mujeres a situaciones incómodas o peligrosas, ya sean insultos, acoso o agresiones. Esta realidad hace que las mujeres marroquíes acaben sintiéndose en peligro en los lugares públicos. Las que pueden permitírselo utilizan el coche aún para los desplazamientos cortos, y otras recurren a estrategias de «supervivencia» como bajar la cabeza, caminar deprisa o no salir tarde, aún a sabiendas de que constituyen medidas restrictivas de su libertad (Zurbano et alii, 2016: 152). Actualmente el cuerpo de las marroquíes, en lo referente a la sexualidad, a la vestimenta y a la libertad para desplazarse «pertenecen a la sociedad marroquí» (Fasiki 2019: 41).

\subsection{La sexualidad}

El segundo capítulo de la obra que analizamos aborda cuestiones muy diversas como la familia y sus modificaciones actuales, las relaciones sexuales, el acoso, las violaciones o la prostitución. La autora incluye su propia reflexión que oscila entre un tono conciliador y un lamento al considerar una «maldición vivir en un país donde nadie te comprende» y donde te consideran una «puta»

(39) En España el matrimonio homosexual se autorizó por ley de 30 de junio de 2005.

(40) pمعية أقليات, página Facebook, creada en enero de 2017:

<https://www.facebook.com/Association.Akaliyat/> [26/10/2019]. 
simplemente por atreverse a hacer lo que le gustaba y por haber sido ella misma (Fasiki 2019: 52). Su caso refleja la situación que sufren muchas personas en Marruecos por no ceñirse a los límites que la religión o la moral pública establecen. Las mujeres son las que más sufren las consecuencias de una mentalidad machista que acaba fomentando el acoso callejero, las violaciones o la violencia, a pesar de que a nivel estatal se hayan conseguido algunas mejoras como la citada ley contra la violencia hacia las mujeres de 2018. Por ello, la educación y la concienciación de la sociedad son fundamentales para provocar un cambio en las mentalidades.

En Marruecos, en materia de educación sexual existen dos posturas contrapuestas. De un lado, un sector islamista conservador, considera que ésta se debe llevar a cabo con un enfoque islamista que perpetúe las reglas, prohibiciones y tabúes existentes. De otro lado, los modernistas, incluidos los movimientos feministas, consideran que es necesario introducir una educación sexual que lleve a la promoción de las mujeres y que permita a los jóvenes asumir una responsabilidad social ante la evidente «transición sexual» que experimenta Marruecos (Gassim, 2015, 103). Mientras tanto, la mayoría de estos jóvenes acceden a la información acerca de la sexualidad a través de internet o hablando con amigos lo que les lleva a adquirir ideas erróneas o a enfrentarse a problemas como las enfermedades de transmisión sexual o los embarazos no deseados. Y es que, a pesar de la prohibición de las relaciones prematrimoniales, son una realidad. Entre los adolescentes urbanos de Casablanca el $60 \%$ de los chicos reconocen haber tenido relaciones sexuales, mientras que solo el $9 \%$ de las chicas admiten haber tenido sexo. Así mismo, un alto porcentaje de estos adolescentes conocen los medios contraceptivos, sobre todo la píldora y el DIU, y el preservativo (Grousset 2002: 257). Otra cuestión es la facilidad para acceder a estos medios, especialmente los que requieran prescripción facultativa. El 31,4\% de los jóvenes encuestados reconoce tener bastantes dificultades para acceder a los anticonceptivos, citando la religión como uno de los principales obstáculos, lo que acaba llevándolos a conductas de riesgo o a la práctica de la abstinencia (ibid.). Los centros de salud, que teóricamente están abiertos a todos los pacientes, ofrecen un servicio de «planificación familiar» que facilita los métodos de control de fertilidad, pero a una categoría «implícitamente definida», es decir, a la de las mujeres casadas. «Una adolescente o una mujer joven soltera del barrio no se expondría jamás a la mirada pública demandando la píldora o preservativos en estos centros, ya 
que su reputación se vería afectada» (Capelli 2017).

Por todo ello, en Marruecos urge poner en marcha una política sexual pública, especialmente en el ámbito educativo por ser donde más se reproducen y ponen en juego las relaciones sociales. El sistema educativo no debe limitarse a la difusión de saberes, sino que es «una herramienta de trasmisión de los modelos de comportamiento social». Al ser la institución oficial encargada de la formación integral de la persona y del futuro ciudadano, se debe de ocupar de «todos los componentes de la personalidad humana, incluida la sexualidad» (Gassim 2015: 99). Sin embargo, la educación sexual es una disciplina marginalizada en los manuales educativos, con una ausencia total de conceptos que reflejen el aspecto social y psico-afectivo de la sexualidad lo cual se refleja en el vocabulario de los manuales carentes de expresiones como deseo sexual, placer, orgasmo o identidad sexual, entre otros, así como de cuestiones como la igualdad de géneros, los derechos sexuales o el consentimiento. El tabú, hshouma, sigue siendo la tónica dominante y la educación sexual se limita al aspecto biológico, instructivo y preventivo (Gassim 2015: 102), pero este enfoque sesgado no es suficiente.

Directamente relacionado con esta cuestión encontramos otro de los prejuicios más arraigados de la sociedad marroquí, la virginidad femenina, al que la obra de Fasiki también hace alusión señalando que a las niñas se les llega a impedir incluso que realicen ciertas actividades deportivas por miedo a la rotura del himen (Fasiki 2019: 89). Los test de virginidad siguen realizándose y cada vez son más frecuentes la utilización de «kits de virginidad artificial» ${ }^{(41)}$ y las operaciones para reconstruir el himen, prácticas muy extendidas en países como Túnez (Ben Dridi 2017). La virginidad, más que una cuestión personal y privada de la mujer, se ha asociado tradicionalmente al honor de la familia. A su vez es uno de los más claros exponentes de la hipocresía existente en la sociedad musulmana con respecto al sexo como lo ejemplifican las declaraciones emitidas en 2019 por el teólogo y diputado marroquí Abdelbari Zemzami que consideraba lícito «el recurso a los hímenes artificiales chinos», ya que basándose en el «principio del bien común», las jóvenes mujeres estarían autorizadas a esconder el «mal menor de su desfloración en beneficio de un bien

(41) Estos kits se pueden adquirir por internet y simulan las condiciones de un himen intacto, incluidos unos colorantes que simularán la sangre tras una relación sexual $<$ https://www.himen-artificial.com/> [26/10/2019]. 
mayor: el matrimonio» (Ben Dridi 2017). El asunto de la virginidad se relajaría si se despenalizaran las relaciones sexuales fuera del matrimonio, sobre todo para los no musulmanes (Fasiki 2019: 100). Aunque también los musulmanes recurren a estrategias para burlar la ley como es la celebración de matrimonios solo reconocidos desde el punto de vista religioso. Estas prácticas, lejos de mejorar la situación de las jóvenes la empeoran ya que se trata de una figura carente de toda protección jurídica.

Bourdieu consideraba acertadamente que la sexualidad era una fuente de dominación masculina lo que significa que las desigualdades en la esfera pública no son más que una prolongación de las desigualdades iniciadas en la esfera privada (Bourdieu 1998). Por ello la implantación de una educación sexual igualitaria sería la herramienta de transformación de las relaciones sociales privadas entre los sexos y como consecuencia contribuiría a la igualdad de géneros en la esfera pública (Gassim 2015: 105-106).

\section{El uso del darija para tratar temas sensibles}

El objetivo principal del proyecto Hshouma es llegar a la sociedad marroquí, sobre todo a los jóvenes, pero también a otros sectores de la población. Su autora, al igual que sucede habitualmente en Marruecos, practica habitualmente el code-switching, es decir, salta sin problemas de una lengua a otra como se aprecia en sus entrevistas ${ }^{42}$. Asimismo, en sus obras recurre indistintamente a varias lenguas y podemos encontrarnos con ilustraciones acompañadas de textos en francés, inglés, árabe clásico y darija, tanto con grafía árabe como latina, incorporando números para las letras árabes.

Al lanzar el proyecto, se hacía hincapié en la utilización del árabe marroquí, al constatar que en el mismo no existen las palabras precisas para hablar de sexualidad. De hecho, las palabras existentes suelen tener una connotación negativa o constituyen insultos, como sucede al mencionar los genitales, pero no existen términos en darija para describir los genitales y otras cuestiones sexuales con objetividad y respeto, lo que dificulta que se puedan romper tabúes sobre cuestiones que no pueden ser nombradas (Fasiki 2019: 7).

(42) Entrevista publicada por H24info.ma el 15 de julio de 2018 $<$ https://www.youtube.com/watch?v=08hDIL4uhwQ> [01/11/2019], entrevista realizada por Welove Buzz el 29 de marzo de 2018. 〈https://www.youtube.com/watch?v=LuyFEuQ4qnc> [01/11/2019]. 
Por ello, se invitaba al público a colaborar en este sentido para poder recopilar un vocabulario específico.

Sin embargo, el uso escrito del darija al tratar de temas tabúes o sensibles no siempre ha dado buenos resultados. En 2006 el periódico semanal Nichane publicó un artículo titulado «Chistes: como los marroquíes se ríen de la religión, del sexo y de la política». Los chistes aparecían tal y como los cuenta la gente en la calle, o sea en darija, y provocaron tal reacción que se prohibió la publicación por considerar que atentaba contra la moral y las buenas costumbres, constituyendo una ofensa a lo sagrado. Lo curioso de este caso es que el mismo texto ya se había publicado antes en francés sin ocasionar ninguna reacción, entonces, ¿el uso del árabe impone el silencio? (Cohen 2011). El uso del francés contrariamente es la «lengua de la libertad» que sin ataduras religiosas permite transgredir los tabúes. Al utilizar el darija, la lengua «hablada» por la población, el tema sensible se «desvela» y es accesible a más gente que no está habituada a tratar estos temas con libertad y de ahí el choque y el escándalo. Política y religión se amparan en el silencio y solo eran accesibles a una élite conocedora del árabe culto, sin embargo, al usar la lengua del pueblo el secreto se pierde.

En Marruecos, la cuestión del público al que se dirige el mensaje juega un papel clave en la elección de la lengua a la hora de tratar temas sensibles. El francés se asocia a valores e ideales de libertad, tolerancia y secularismo, diferentes a los de la lengua árabe. Los lectores arabófonos suelen proceder de medios populares y burgueses con un mayor apego al islam y a la monarquía, temas con los que son menos críticos que los francófonos (Cohen 2011). El uso del darija, permite a las clases populares acceder a los temas tabúes, pero es un acto «transgresor» ya que les permite alcanzar unos conocimientos controlados por la élite. Pasar de «lengua popular»a «lengua culta» implica una nueva forma de poder (ibid.).

Otra situación de «mal recibimiento» del darija se debió a la introducción por el Ministerio de Educación de ciertas expresiones en los manuales escolares de 2018 que fueron tachados de «manuales de la indecencia ${ }^{(43)}$ ». La campaña surgió de las redes que se inundaron de falsos fotomontajes incluyendo fotos y expresiones de libros extranjeros con la idea de desprestigiar los manuales. En

(43) Noticia publicada el 11/09/2018 en <https://observers.france24.com/fr/20180911-marocdialecte-manuels-scolaires-intox-photos $>$ [29/10/2019].

$A A M, 26$ (2019) 09.1-24 
realidad, sólo se trató de incluir «ocho palabras en un manual de 150 páginas y 8000 palabras», referidas principalmente a especialidades culinarias. Lo llamativo de este asunto es que esta decisión provocó la reacción de los diputados conservadores que consideraron vulnerada la Constitución, que en su artículo $5^{(44)}$, solo reconoce dos lenguas oficiales, el árabe y el bereber.

Estos dos ejemplos ayudan a entender mejor lo ambicioso del proyecto de Fasiki, que pretendía que la plataforma digital estuviera en darija, a pesar de las reticencias existentes con respecto al uso del dialecto para tratar temas controvertidos. Sin embargo, la plataforma se lanzó inicialmente en inglés, y finalmente, su impulsora se decantó por el francés al constatar las dificultades de usar el dialecto marroquí por la falta de vocabulario y, quien sabe, si por un cierto temor a crear una mayor polémica al atacar frontalmente a los tabúes más arraigados recurriendo al árabe.

\section{Conclusiones}

El proyecto Hshouma constituye una apuesta arriesgada e innovadora en el marco de un sector conservador de la sociedad marroquí y más aún al estar liderado por una mujer joven que ha osado reivindicar su libertad para expresarse artísticamente como medio de hacer reflexionar a la sociedad y romper los tabúes existentes. Su peculiar manera de protestar, utilizando el desnudo en sus dibujos como herramienta, pretende liberar el cuerpo femenino y naturalizar el desnudo desvinculándolo del sexo. Lograr que su arte burle la censura ya supone un gran paso en su lucha ya que, a pesar de las críticas, su mensaje ha conseguido una amplia repercusión internacional. Sin duda se trata de un proyecto valiente, en el que la autora se salta los convencionalismos más arraigados esperando la respuesta de la sociedad. Su obra constituye además un sucinto recurso didáctico y un testimonio personal en el que expone sus puntos de vista sin intención de convencer a quien no los comparta, pero con la idea firme de lograr una sociedad plural en la que quepan todos los planteamientos para alcanzar una convivencia pacífica, algo bastante utópico si tenemos

(44) La reacción de estos diputados no tiene base jurídica ya que el artículo 5 de la Constitución de 2011 establece que el árabe es «la» lengua oficial del Estado, y que el amazighe constituye «una» lengua oficial del Estado. Además, establece que el Estado trabaja en la protección de las «hablas y expresiones culturales practicadas en Marruecos», lo que justificaría la inclusión de estas expresiones controvertidas en el manual objeto de la polémica. 
presentes la existencia de posiciones conservadoras y nada tolerantes con las opiniones divergentes de la moral pública, sobre todo si confunden conceptos como pecado y delito.

Iniciativas como el proyecto Hshouma contribuyen a sensibilizar a la población, reabren el debate y constituyen un paso más hacia la defensa de las libertades individuales, la gran asignatura pendiente en Marruecos.

\section{BIBLIOGRAFIA}

ÁVALOS, Almudena. 2018. «Zainab Fasiki: cómo derrocar al patriarcado marroquí con un simple lápiz». El País (19 de julio de 2018) <https://bit.ly/2MVCEeQ> [30 de octubre de 2019].

BEN DRIDI, Ibtissem. 2017. «Les réfections chirurgicales de l'hymen en Tunisie. Des techniques de purification et d'absolution?». L'Année du Maghreb, 17, pp. 119-132,

<http://journals.openedition.org/anneemaghreb/3208> [30 de octubre de 2018].

BOURDIEU, Pierre. 1998. La domination masculine. París, Éditions du Seuil.

BOZONNET, Charlotte. 2018. « Au Maroc, un colloque sur les libertés individuelles interdit par manque de courage politique ». Le Monde Afrique, 21 de junio de 2018. <https://bit.ly/32YNCFV> [30 de octubre de 2019].

CAPELLI, Irene. 2017. «Les enjeux et les déclinaisons de la notion de santé sexuelle et reproductive au Maroc. Réflexions à partir du cas des grossesses hors mariage ». L'Année du Maghreb 17, pp. 83-99.

$<$ http://journals.openedition.org/anneemaghreb/3191> [26 de octubre de 2019].

COHEN, Anouk. 2011. « La langue du silence dans le Maroc urbain contemporain ». Revue de l'histoire des religions 2, pp. 245-263. <http://journals.openedition.org/rhr/7779> [9 de abril de 2019].

DEUXARD, Jane \& DELOUPY, Zac. 2016. Love story à l'iranienne. Delcourt, 
París.

EL ADNANI, Abir. 2018. «Diapo. Zainab Fasiki signe une BD en darija sur l'éducation sexuelle ». H24info. Culture, 3 de junio de 2018. <https://bit.ly/2MUlMF0> [26 de octubre de 2019].

GARRATÓN MATEU, Carmen. 2017. «Mujer y herencia en el contexto musulmán y bereber norteafricano». Al-Andalus Magreb 24, pp. 47-66.

HUMAN RIGHTS WATCH. 2018. Audacity in Adversity. LGBT Activism in the Middle East and North Africa.

LACOSTE-DUJARDIN, Camile. 1985. Des mères contre les femmes. Maternité et patriarcat au Maghreb. París, Éditions La Découverte.

FASIKI, Zainab. 2019. Hshouma. Corps et sexualité au Maroc. París, Massot Éditions.

FASIKI, Zainab. 2018a. Hshouma. Madrid, Matadero / AECID.

FASIKI, Zainab. 2018b. Feyrouz versus the world. Beirut, Tosh Fesh.

GASSIM, Zouhair. 2015. «Genre et Éducation Sexuelle Dans le Système Éducatif Marocain ». Kohl: a Journal for Body and Gender Research, vol. 1, 2, pp. 98-107.

GROUSSET, Jocelyne. 2002. «Adolescence marocaine en milieu urbain » Sante Publique 14, 3, pp. 253-262.

OSSMAN, Susan. 2002. Three Faces of Beauty: Casablanca, Paris, Cairo. Durham, Duke University Press.

REVERTER BAÑON, Sonia. 2016. «El feminismo dislocado: el caso FEMEN». Eikasia. Revista de filosofía, pp. 161-187.

SLIMANI, Leila \& CORYN Laetitia. 2017. Paroles d'honneur. París, Les Arènes BD.

TOPPER, Ilya U. 2019. «Zainab Fasiki: Hshouma. Viñetas desde Marruecos». M'Sur,

<https://msur.es/2019/04/12/zainab-fasiki-hshouma/> [26 de octubre de 2019].

VELASCO DE CASTRO, Rocío. 2019. «Grafismo e igualdad de género en Marruecos: Hshouma, de Zainab Fasiki». Akademía. Revista Internacional y Comparada de Derechos Humanos 2, 1, pp. 13-53.

UNITED NATIONS DEVELOPMENT PROGRAMME (UNDP). 2016. Arab Reading Index 2016, <https://bit.ly/32ZrFX0> [26 de octubre de 2019].

WOMEN POWER \& JAWJAB. 2018. Drawing a guide to stop street harassment. Rabat, Fondation Friedrich Naumann Pour La Liberté. 
WORLD ECONOMIC FORUM. 2018. Global Gender Gap Report 2018.

<http://reports.weforum.org/global-gender-gap-report-2018/> $\left[\begin{array}{ll}26 & \mathrm{de}\end{array}\right.$ octubre de 2019].

ZURBANO BERENGUER, Belén, LIBERIA VAYÁ, Irene \& BOUCHARA, Aicha. 2016. «Acoso sexual callejero y estrategias comunicativas. Un análisis comparado entre España y Marruecos». Comunicação, Mídia e Consumo 13, 37, pp. 138-159. 